\title{
Exploring the perceptions of Malaysian Gen Z towards the impact of COVID-19 on sustainable development
}

\author{
Stephen T. Homer ${ }^{1}$ (1) $\cdot$ Kuan Siew Khor $^{1}$ (D)
}

Received: 8 July 2021 / Accepted: 22 November 2021 / Published online: 26 November 2021

(c) The Author(s), under exclusive licence to Springer-Verlag GmbH Germany, part of Springer Nature 2021

\begin{abstract}
COVID-19 has affected the pursuit of sustainable development in multifaceted ways; this study investigates Malaysian Gen Z perceptions of the COVID-19 pandemics' disruptions to sustainable development. The exploratory research began with brainstorming from Malaysian Gen Z individuals with the following excerpt, 'The COVID-19 pandemic has disrupted the world and led to unprecedented change. How do you believe this has impacted either positively or negatively, the global pursuit of sustainable development?' Ninety-eight unique statements were generated with subsequent participants sorting these statements into thematic groups before rating each of them on impact and duration. Subsequently, multi-dimensional scaling and cluster analysis was performed with eight-cluster solution being proposed. This study suggests that the pandemic has contributed both positively and negatively to sustainable development, while also highlighting the duration of these impacts. This community-based participatory research provides a guide for policy to mitigate negative impacts whilst also attempting to fully realise the positive impacts in response to managing the unprecedented effects of the pandemic.
\end{abstract}

Keywords Sustainable Development $\cdot$ COVID-19 $\cdot$ Pandemic $\cdot$ Concept mapping $\cdot$ Hierarchical cluster analysis

\section{Introduction}

Unsustainable development puts humanity at risk and now many communities across the globe are experiencing unprecedented challenges due to the COVID-19 outbreak. Extensive deforestation, agricultural expansion and infrastructure development have resulted in the exploitation of wild life and nature and somehow animal-borne viruses have found its way to make humans sick (Davidson, 2020). From the interest of sustainable development, the mass disruption to the business-as-usual urgently calls for sustainability to be built into the comeback. For instance, a recent article from the Intergovernmental Platform on Biodiversity and Ecosystem Services (IJPES) suggested that business-asusual should allay for the impact of pandemic due to the

Responsible Editor: Ioannis A. Katsoyiannis

Stephen T. Homer

stephenhomer@sunway.edu.my

Kuan Siew Khor

kuansiewk@sunway.edu.my

1 Management Department, Sunway University Business School, Sunway University, Subang Jaya , Malaysia likelihood for future pandemics (Settele et al., 2020). World Livestock 2013 report by the United Nation's Food and Agriculture Organization (FAO) suggested that $70 \%$ of the novel pathogens/diseases emerging in humans are zoonotic in nature. There are about 1.7 million unidentified viruses capable of infecting humans that are residing in mammals and water birds (Davidson, 2020). Furthermore, we have not accounted for ancient viruses that have been locked away but now released from the melting of glacier and permafrost due to global warming (Glick, 2004). Therefore, how about viewing the COVID-19 pandemic as an opportunity to hit the reset button to resume the pursuit of sustainability and rebuild a global economy that prioritises the triple bottom line while inheriting resilience that comes with this experience? This study thus adopts a grounded theory approach to explore the impacts of the COVID-19 pandemic on efforts of sustainable development in a developing country, namely Malaysia.

Like most developing countries, the Malaysia Government pursue rapid economic and technological development with environmental sustainability coming second to profit maximisation. Malaysia is recognised as a biodiversity hotspot (Convention on Biological Diversity, 2020); however, the many mammals are potential virus carriers. The 
interaction between humans and nature is inevitable and the adaptability of viruses in the human-wildlife interfaces has resulted in several outbreaks that have caused illnesses or deaths and major economic losses. Back in the year 1999, the Nipah virus outbreak in Malaysia [a viral infection carried by fruit bats] spilled over into a large pig farm in Negeri Sembilan. Wild fruit bats fed on the fruit trees and the pigs became contaminated by infectious bat saliva, urine and faeces. Many of the patients who were infected worked in close contact with the infected pigs and 105 out of 265 patients did not survive the virus (Ang et al., 2018; WHO, 2018). Thus, the Nipah virus reported a case fatality rate between 40 and $75 \%$ (Gill, 2020). The case fatality rate of the coronavirus is still emerging, and the current estimates is under $1 \%$. However, the continued encroachment upon nature through a lack of sustainability seems to indirectly suggest that we should brace for the emergence of other infectious viruses if we do not adopt pro-environmental behavioural change.

Despite so, the pursuit of sustainable development could be inhibited by economic recession owing to the financial shock from the COVID-19 pandemic. Although it will take some time for the economy to recover to pre-crisis condition, this study intends to 'reverse the lens' to explore the positive or negative impacts of the COVID-19 pandemic on sustainable development from the perspective of Malaysian Gen Z. The study was conducted during the Movement Control Order (MCO) that was imposed throughout the country between April and July 2020. The national lockdown was a preventive measure to mitigate the risk of virus transmission and permitted travelling only for businesses that are categorised as essential services, or critical services for public health or safety set forth by the Prevention and Control of Infectious Diseases (Measures with the Infected Local Areas) Regulations 2020. The views of Malaysian Gen Z (those born in or after 1997) are targeted because they are expected to be more adaptive to technological innovation and will become future leaders who will develop and implement sustainability policies. It is also important not to forget that Gen $\mathrm{Z}$ is implicated by national debt accumulated by governmental measures to cope with the economic shock of the COVID-19 pandemic.

The adopted methodology of concept mapping was decided upon as the best method to accommodate the study's exploratory nature. An initial qualitative phase allowed for new or adapted ideas upon Gen Z's perspective of sustainable development, followed by the mapping process where ideas were statistically brought together based on participants' cognitive grouping of statements. The main advantage of concept mapping is that it leads to objective results from subjective group dynamics by a combined use of techniques, including; multi-dimensional scaling and cluster analysis (Bigné et al., 2002). The study not only offers an insight into the concept of sustainable development from the perspective of Malaysian Gen Z but also how the unprecedented impact of COVID-19 has taken upon sustainability efforts. With much discussion in the media around adopting 'the new norm', Gen Z may well be inheriting a very different world when compared to pre-COVID-19 period. This study highlights the challenges and opportunities from their perspective and implications to existing policies. This study contributes to existing literature by accommodating intangible elements based on subjective perceptions to complement existing objective researches. Hansen et al. (2016) pointed out that people tend to act based on their perceptions more reliably than on objective reality. Therefore, due considerations must be given to subjective perceptions to achieve an environmentally sustainable future.

The paper continues with a literature review; however with the pandemic being a new and dynamic phenomenon that is still emerging, literature is scarce and likely to change. Proceeding this, the selected method of concept mapping is examined followed by the results. The subsequent section of discussion then attempts to interpret the findings from this exploratory study before the study is concluded.

\section{Literature review}

Malaysia poses an exceptionally attractive context to examine sustainability efforts as the nation progresses towards becoming a high-income country by 2024 (The World Bank, 2020). Like many developing countries, economic growth has been accompanied by a lack of commitment towards sustainable practices and social responsibility within companies (Amran \& Devi, 2007). There have been noticeable neglected environmental issues despite the existence of environmental policies (Zulkifli \& Amran, 2006; Preuss et al., 2016). During the pre-COVID-19 period, Malaysia concentrated on a comprehensive development towards becoming a developed nation by committing to economic development and economic social justice (Mahathir, 2008). Thus, presenting an enticing opportunity to investigate not only sustainability practices but also perception of what sustainability consists of. Furthermore, current sustainability literature that focused on the perspectives of Southeast Asian communities is lacking. Therefore, the Malaysian context offers unique insight whilst also offering a different values system compared to Western values, which are generally based on Judeo-Christian (Idemudia, 2011).

This section presents a chronological list of events to clarify the context of the study in greater detail. On the last day of 2019, a media statement reported cases of 'viral pneumonia' in Wuhan, China, known as 2019-nCoV (World Health Organization, 2020a, 2020b). Whilst the initial outbreak was primarily contained within China, the 
virus had crossed international borders and was spreading rapidly, leading to Malaysia imposed a travel ban from Chinese provinces placed on lockdown from the 6th of February. Due to the continued outbreak, the WHO declared a pandemic on 11 March 2020. The Malaysian Prime Minister announced the implementation of Movement Control Order (MCO), otherwise known as lockdown from 18 March to restrict movement of people so as to mitigate the spread of the virus. Upon subsequent extensions, the restrictions were revised on 4 May and Movement Control Order (CMCO) was introduced to revive the economy whilst also taking precautions against a resurgence in the spread of the virus. Within this time, frame mask wearing became mandatory and the government introduced the track and trace app 'MySejahtera'. The combination of source control and mask wearing, demonstrated here by the Malaysian government, had showed high efficiency in the sustainable epidemic and environmental transmission risk control developed by $\mathrm{Yu}$ et al. (2021). This study was conducted during this period, when $\mathrm{MCO}$ and $\mathrm{CMCO}$ were in place, where the effect of the virus upon day-to-day life was at its most prominent. Whilst Malaysia's prolonged lockdown and movement restrictions may have reduced the spread of COVID19 , the fatality rate of those infected may actually have increased. This is because Coccia (2021e) suggests that during the first wave of COVID-19 pandemic, countries with a shorter period of lockdown have average fatality rate lower than countries with a longer length of lockdown.

Owing to globalisation, the pandemic has knock-on effects on countries who are not severely affected by the viral infections due to the interdependence between both local and international supply chain partners. An IPSOS (2020) study asked fourteen countries whether, 'In the economic recovery after COVID-19, it's important that government actions prioritize climate change', to which $65 \%$ agreed to the statement. China and India were among top three agreeing nations, suggesting that Asian nations are ready to break the business-as-usual practices post-COVID-19. However, when asked whether the government should focus on economy despite negative environmental impacts, $63 \%$ of Indians agreed whereas $59 \%$ of Chinese participants disagreed to the idea, thus suggesting differences in economic recovery approaches. For Malaysia, the initial economic recovery involved RM20billion (US\$4.8billion) financial stimulus package aimed to lessen the effect of COVID-19, assist people-based economic growth and encourage quality investments (Shah et al., 2020). Thus, the Malaysian stance on economic recovery over environmental concerns is unclear.

The disruption caused by the COVID-19 pandemic has led to many changes which have had positive and negative effects upon life and the pursuit of sustainable development. Some of the positive effects include, but are not limited to;
$\mathrm{CO} 2$ emissions reduced by an estimate of $6.4 \%$ compared to the global total in 2019. Cities and towns across the world undertook lockdown to control virus transmission. The coronavirus crisis records the first ever dip in carbon emission in 2020, more than during any previous economic crisis or period of war (Tollefson, 2021). Further studies suggest daily global $\mathrm{CO} 2$ emissions decreased by $17 \%$ in early April 2020 compared against 2019, with the peak by individual countries decreased by an average of $26 \%$ (Le Quéré et al., 2020). This reduction was primarily contributed by the aviation sector where daily activities reduced by $75 \%$, surface transport activities reduced by $50 \%$ and industry and public sectors activity reduced by $35 \%$ (Le Quéré et al., 2020). There was significant improvement in air quality (Rume \& Islam, 2020; Kumari \& Toshniwal, 2020). In fact, ASEAN's transboundary haze issue did not make headlines in 2020. This reduction in CO2 and pollution could have an additional benefit, as Coccia (2021b) suggests that high concentrations of air pollutants may promote a longer permanence of COVID-19 viral particles in polluted air of cities, thus assisting indirect means of diffusion. Nevertheless, this downward trend appears temporary as countries attempt to revive their economies after extended periods of 'lockdown'. The battle against COVID-19 impelled change in the management of businesses to accommodate stay-athome restrictions.

Wildlife Recovery has taken place as national lockdowns reduced human activities. As the coronaviruses are zoonotic and can spill over to the human population through wild animals and livestock, Borzee et al. (2020) recommended that government legislations must be effective in protecting wildlife and their habitat, including regulating the wildlife trade. In 2020, dolphins were spotted further up the Bosphorus in Istanbul, Turkey, which is normally one of the world's busiest marine routes (BBC News, 2020). In the East Coast of Peninsular Malaysia, there was more than 70\% increase in turtle landings at the sanctuaries compared to the same period in the previous year (Bernama, 2020). With less human interference, wildlife appears to be venturing back into domains which were once theirs. The changes in land use for agriculture tipped the balance in the relationship between wildlife-livestock-human. These pre-existing issues and the exploitation of wildlife for trading continues to trigger the onslaught of infectious disease. The COVID19 pandemic made the world pay attention to the risks of zoonoses.

Some of the negative impacts of the corona virus crisis include but are not limited to:

A turndown of the global economy, with the FTSE, Dow Jones Industrial Average and the Nikkei have all seen huge falls since the outbreak began on 31 December 2019. The Dow and the FTSE saw their biggest quarterly drops in the first three months of the year since 1987 (Jones et al., 2020). 
The prices of gold surged to a record high of USD 2070 per ounce in August 2020 as investors opted for safe-haven investment to hedge against inflation. There are suggestions that the developing nations will be the hardest hit through a combination of the following: a fall in commodities prices (i.e. oil), withdrawal of international investment, increase in foreign debt as local currency is devalued, unable to conduct informal work (i.e. street vendors) or a decline in remittances being sent to home country (Walker, 2020). The Asian Development Bank suggests that developing Asian economies are going to be particularly affected through sharp declines in domestic demand, lower tourism and business travel and/or supply disruptions (Abiad et al., 2020).

Unemployment had increased after countries across the world implemented lockdowns or restricted movement to control non-essential travel in effort to contain the COVID19 outbreak; albeit effective, it takes toll on survival and continuity of businesses. This unprecedented situation led to massive job losses across many industries. In the USA, the unemployment rate hit a record high where an estimated thirty million people filed for unemployment benefits in 6 weeks between the March and May 2020 (Jones et al., 2020), signalling the end to a decade of job growth for one of the world's largest economy. The Department of Statistics of Malaysia reported that unemployment rate increased to $4.8 \%$ as of Dec 2020 and this is significantly higher compared to an average of 3.3\% in the last two decades (DoSM, 2020). The number of jobs required by private sector declined by 204,000 when compared to the year before. This could be attributed to some 32,000 small and medium enterprises (SMEs) that closed during MCO (Tan et al., 2020). In fact, the service industry offers more that $50 \%$ of jobs in the market and restriction of movement pose difficulties to business as usual, suggesting that imminent change is required for business continuity.

Plastic pollution has been a challenge even for developed nations and through the pandemic, there has been increase use of single use plastic (SUP) and medical plastic waste (MPW) across the world (Mallick et al., 2021). Mallick et al. highlighted that the contagious nature of the COVID-19 virus has contributed large volume of SUP and MPW refuse, making the dumping and incinerating places an increasingly hostile environment. Malaysia already generates high plastic waste per capita and reported poor recycling rate during pre-COVID-19 period (MESTECC, 2019). Tons of SUP and MPW have been generated throughout the pandemic especially personal protective equipment e.g. gowns, gloves and face masks (Hughes, 2020). Higher demand for virgin plastic is observed with lower oil price. The market for recycled plastic is further exacerbated in Europe and the USA, where the plastic industry that has always capitalised on threat of cross-contamination in reusable plastics have since benefitted from the COVID-19 situation due to the pushback on the policy to ban SUP products (Scaraboto et al., 2020). Companies like Starbucks banned reusable mugs temporarily, forcing customers to accept single use mugs (Carey, 2020). In reality, this situation stemmed from inadequate sanitisation system for take-out foodstuff.

While the abovementioned issues are non-exhaustive, recovery plans have been unveiled to contain the impact of COVID-19. The International Institute of Sustainable Development suggested that recovery must consider three key points; that is resilience must be built into the system, economic stimulus needs to be sustainable, and the magnified inequality must be addressed (Florizone, 2020). A study by Coccia (2022) suggested that during the recovery period, countries will need to increase spending on research and development for equipment, infrastructures and education within the healthcare sector to improve preparedness to react with differing COVID-19 variants as well as risk of future pandemic threats. Thus, the recovery approach adopted by Malaysia needs to incorporate a cautious and resilient policy to cope with possible resurgence or new pandemic. The following section discussed the methodology that was adopted to explore the impact of COVID-19 upon Malaysia's sustainability efforts.

\section{Methodology}

This study focused on Malaysians who were born between 1997 and 2003, also known as Gen Z. They are more techsavvy than the previous generations and have begun to inherit the sustainability and climate change challenges. The idea of capturing the thoughts of Gen $\mathrm{Z}$ is alluring because their perceptions of sustainability today will drive the regulative policies of tomorrow. Whilst Gen $\mathrm{Z}$ may not have the experience or knowledge of contemporary leaders or academics to tangibly interpret the complexities of sustainable development, this generation have greater awareness towards United Nation's sustainable development goals (UNSDG). This can be encapsulated by individuals such as Greta Thunberg and the proceeding movement of School Strike for Climate which is also known as Fridays for Future. Gen $\mathrm{Z}$ are also likely to have to pay for the effects of climate change, as government advisers in the UK warned in a report (Harrabin, 2018) that this is not isolated to the UK considering that climate change is a global phenomenon. Thus, Gen Z also have a vested interest within sustainable development.

Concept mapping approach was chosen because the initial phase involved bottom-up exploratory research design where individual ideas are generated via brainstorming based on grounded theory. Subsequently, the concept mapping process progressed with statistically bringing the ideas together by cognitively grouping them to develop a visual conceptualisation. The process of concept mapping involves 
five stages: create statements, sort statements, run multidimensional scaling (MDS) of sorted units, run hierarchical cluster analysis (HCA) and label the clusters (Kane \& Trochim, 2007). The concept mapping process is a structural conceptualization method designed to organize and represent ideas from an identified group (Rosas \& Kane, 2012). Therefore, the method adds structure to diverse and subjective ideas systematically. The concept mapping approach is supported by grounded theory. In which grounded theory is the research process of being guided by knowledge gathered during the study and not by conventional practices (Sarantakos, 2005), this was deemed essential for the proposed exploratory nature of the study, as there was a desire to capture new knowledge that may be overlooked by conventional practices.

Create statements The Concept System ${ }^{\circledR}$ Global MAX $\odot$ browser-based software that was used for this study offers an online brainstorming tool which was utilised for the initial collection of statements. This embedded tool within the software consists of a page which presents the 'prompt' question, a text entry box and a list of prior entries from all participants. This allows participant ideas to build from one another as all entries are visible, whilst at the same time minimising duplicate ideas which reduces the need to minimise the number of statements to the desired 80 to 100 statement. Whilst preferably focus groups would have been used to generate statements, with COVID-19 restrictions in place, this was not possible. Another option is to use questionnaires to generate statements; however, the issue here is that they are conducted in isolation, meaning participants cannot feed or build upon one another's ideas. Additionally, questionnaires would generate a significant number of redundant statements which would need to be removed, contributing further subjectivity. It was because of these issues with focus groups and questionnaires that the online brainstorming tool was opted for as the best option. An online poster was created to solicit responses from Malaysian Gen $\mathrm{Z}$ through various social media outlets. The brainstorming prompt question was 'The COVID-19 pandemic has disrupted the world and led to unprecedented change. How do you believe this has impacted, either positively or negatively, the global pursuit of sustainable development?'. No limit to the number of participants was set as the software only tracked those who followed the link rather than those who actually contributed, thus a fixed period of one month was adopted for any participants who fit the criteria of Malaysian Gen Z. The number of statements collected was then reduced based on Keyword In Context (KWIC) technique, followed by thematic analyses to present a list of ideas composing of preferably 80 to 100 statements (Homer, 2021). The KWIC process is done through a search for the same words repeated in statements and grouped together to look for double redundancy, whilst thematic looks for words with similar meanings, e.g. environment and nature, where these are then grouped together and reviewed to eliminate redundancy. This process was appraised by both researchers to ensure the statements are shortlisted effectively and impartially to minimise bias.

Sort statements The software was used to facilitate online sorting with Rosas and Kane (2012) recommending twentyfive to thirty participants for this stage. This had been empirically tested within the study where number of participants beyond thirty had very little, if any affect upon the stress value reported by multi-dimensional scaling (MDS) performed in the subsequent stage of the concept mapping process. A call for thirty participants through social media was put out with participants being screened based on the criteria of being Malaysian and also Gen Z. The e-sorting of statements using the Concept System ${ }^{\circledR}$ Global MAX $\subset$ browser-based software involved grouping statements into piles that makes sense to the individual. Researchers provide minimal guidance to participants during this stage so that they can express their inherent cognitive relationships amongst the statements. The participation information sheet provides guidance to enable this process such as participants cannot single out any statements, participants cannot put all statements in one pile and neither can participants form a pile for miscellaneous. Participants are required to name the groups they have formed. Subsequently, they rated the Impact ( -3 : strong negative impact to 3: strong positive impact) and Duration (1: very short term to 7: very long term) of each statement. The sorting exercise consists of 'drag and drop' meaning it is very intuitive and user friendly whilst the two rating exercises for impact and duration were executed based on conventional survey format.

Run MDS and HCA The data collected from the sort and rate exercises were analysed using The Concept System ${ }^{\circledR}$ Global MAX(C. The software runs MDS to generate 'point map' for all the groups of statements. This means that statements that are positioned closer together were repeatedly sorted into the same pile by participants, whilst those 'points' or statements which are farther apart were less often, if at all, grouped together by participants. The MDS must force the data to fit within two-dimensional space to generate the point map. This creates 'stress' value and Sturrock and Rocha (2000) suggested that the upper limit of the stress value should be 0.39 , providing only $1 \%$ chance of items having a random arrangement. Next, the HCA was generated, however there is no definitive solution to the number of clusters that should be duly chosen for this research. The Concept System ${ }^{\circledR}$ Global MAX@ also incorporated a cluster playback function which allows the researchers to review each reduction in the number of clusters and evaluate the appropriateness of the reduction. Being HCA, the hierarchical component means 
that each reduction in the number of clusters is statistically generated by merging the two most similar clusters and this reduces some subjectivity in the decision making. The selection of number of clusters is a multifaceted decisionmaking process that considered the research objective, the issue being investigated and the sensibility of the statements belonging together (Homer \& Khor, 2021; Kane \& Trochim, 2007). Both the clusters and the point maps were carefully reviewed and evaluated between the researchers to mutually agree on the cluster map solution.

Label clusters Cluster names from individual respondents were collected during the sort statements stage. Thereafter, the Global MAX software generated the top ten most commonly used labels for each cluster and the researchers were given the option to adopt or adapt the most appropriate name upon reviewing the content within respective cluster.

\section{Results}

The brainstorming stage generated 115 ideas or statements, which were then reduced to 98 unique statements. This consisted of a reduction of 13 statements through KWIC technique and a further reduction of 5 statements through the thematic analysis. The brainstorming tools allow participants to view the pool of statements submitted by previous participants and this enabled an effective gatekeeping to minimise redundancy in the data collected. Whilst the list of statements presented in Table 1 is considerably large, the diversity of ideas resulting from the brainstorming exercise did not enable further reduction to minimise the risk of losing content. Next, thirty participants were recruited to participate in the sorting and rating exercise. The results from the MDS reported a stress value of 0.3238 , which is within the acceptable threshold of 0.390 (Sturrock \& Rocha, 2000). This reasonably high stress value could be attributed to the diverse nature of the statements. Figure 1 presents the point map that shows the location of all statements, with statements which are closer together have been grouped more frequently by participants. Figure 1 presented clear clustering of points, particularly in the top and bottom right-hand side, and this demonstrated participants' cognitive view towards the relationships amongst these statements. However, those statements on the left of the figure appeared more spread out and this indicated that participants may have experienced slight uncertainty on how these statements interact. Next, the number of clusters was deliberated between researchers and eight clusters appeared to be the most meaningful solution. The most fitting labels to cluster were then adopted and/or adapted from a list of names generated by participants (refer to Table 1 and Fig. 1). The average ratings with regard to impact and duration for each cluster and individual statements are also presented by Table 1 .

The ratings for impact and duration were presented differently from the typical concept mapping approach where each cluster is usually represented by stacked of layers upon the concept map. Instead, Fig. 2 presents the results using the scatterplot with $\mathrm{x}$-axis (duration) and $\mathrm{y}$-axis (impact), where the mid-point for both ratings divided the statements into four quadrants. The quadrants, moving from the top right to the top left quadrant in clockwise direction, are categorised as long-term positive impacts, long-term negative impacts, short-term negative impacts and short-term positive impacts, respectively. Whilst the scales on this plot are subjective, being based upon the individual's perspectives, the clustering of statements, as well as the outliers, allow for interpretation. Beginning with the short-term impacts, there is more clustering of both positive and negative impacts towards the mid-point (axis) which suggested that these impacts are more towards a moderate time frame, rather than an actual short-term duration. Within the positive impact, a second cluster was located slightly further away from the axis towards the longer term. The long-term, negative impacts appeared to have a downward trend, where the larger the perceived negative impact, the longer the perceived duration of these impacts. Looking at the extremes of Fig. 2 further revealed that the shortest duration and slightly negative perceived impact is statement \#86 People who practice religion have struggled to fulfil their spiritual needs with places of worship being closed, which will be resolved quickly as soon as lockdowns are lifted. Whilst on at the other extreme, with a longer duration and largest perceived negative impact would be statement \#16 Low income group face highest risk of not being able to bring food to the table. The issue faced here is that until a sustainable global economic recovery takes place, the employment growth will also take time to make up for the losses suffered over the last 2 years.

The positive impacts, with the exception of a few outliers, appears to take a more horizontal format within the positive values of 1 to 2.5 . There further appears to be two concentrations of the positive impacts within durations, one between 3 and 3.5 impact ratings and another between 4 and 5 impact ratings. The values here tend to move away from the short term with those in the 1st cluster being mid-term duration, as they are next to the central axis, whilst the second grouping appears to be moving towards the longer term. Thus, the pattern here is in stark contrast to the negative impacts. There are also three statements within the positive impact which are outliers and appear to have a prolonged duration to other positive impacting statements. These are \#3 Pandemic has pushed the development of $5 G$ network to improve IT infrastructure, \#28 COVID-19 pushed the 4th industrial revolution with working from home and automation and, \#71 The UN Sustainable Development Goals are 
言翊

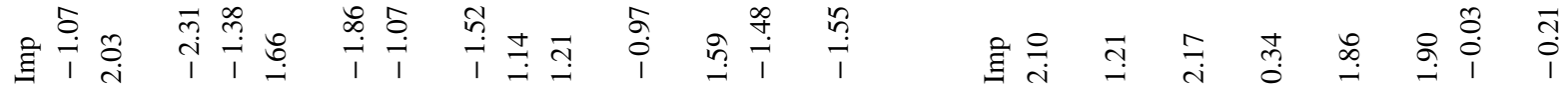

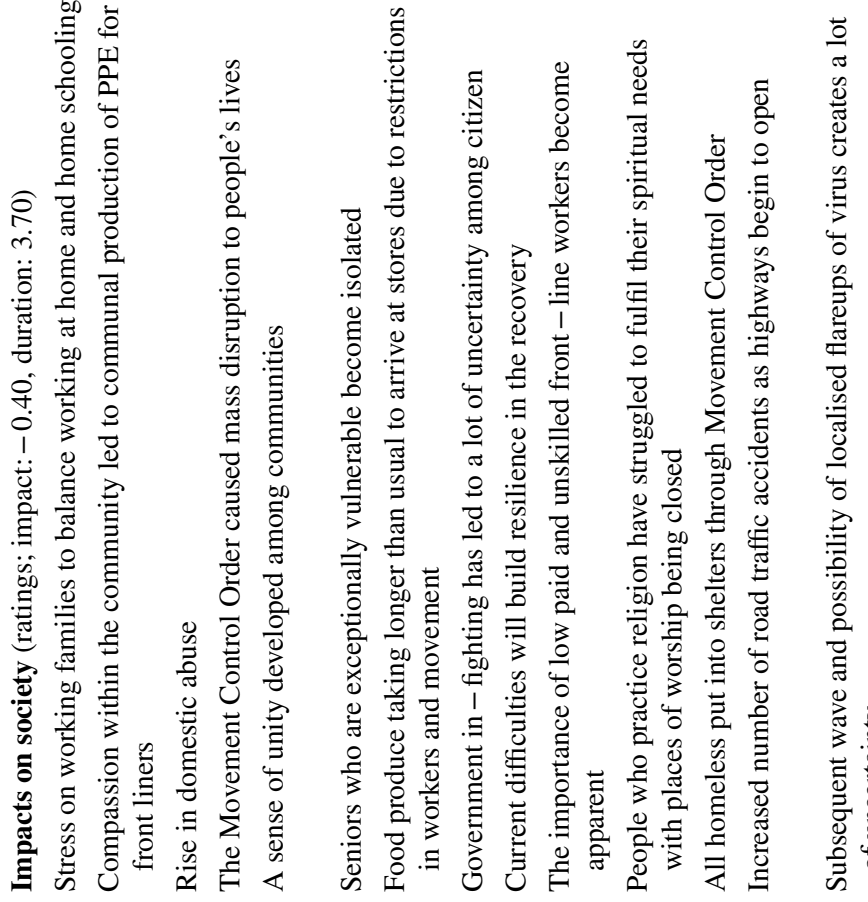

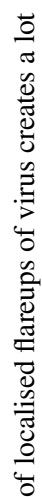

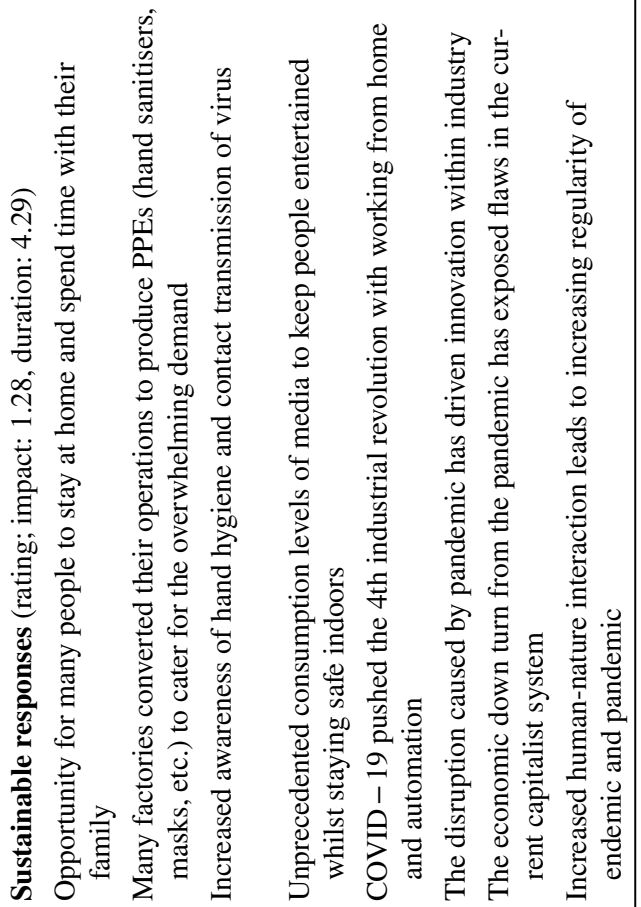

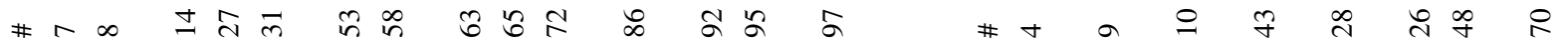

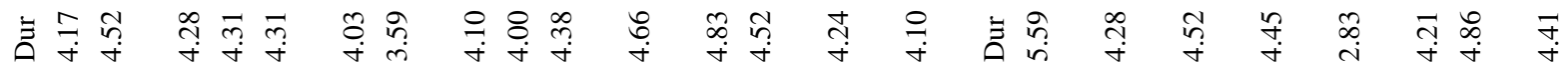

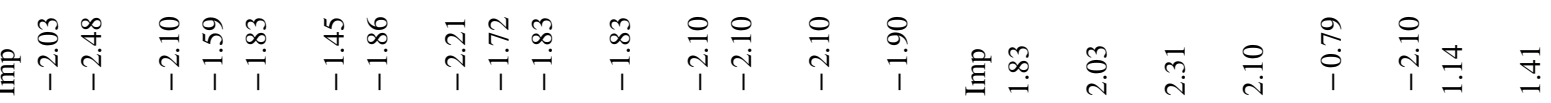

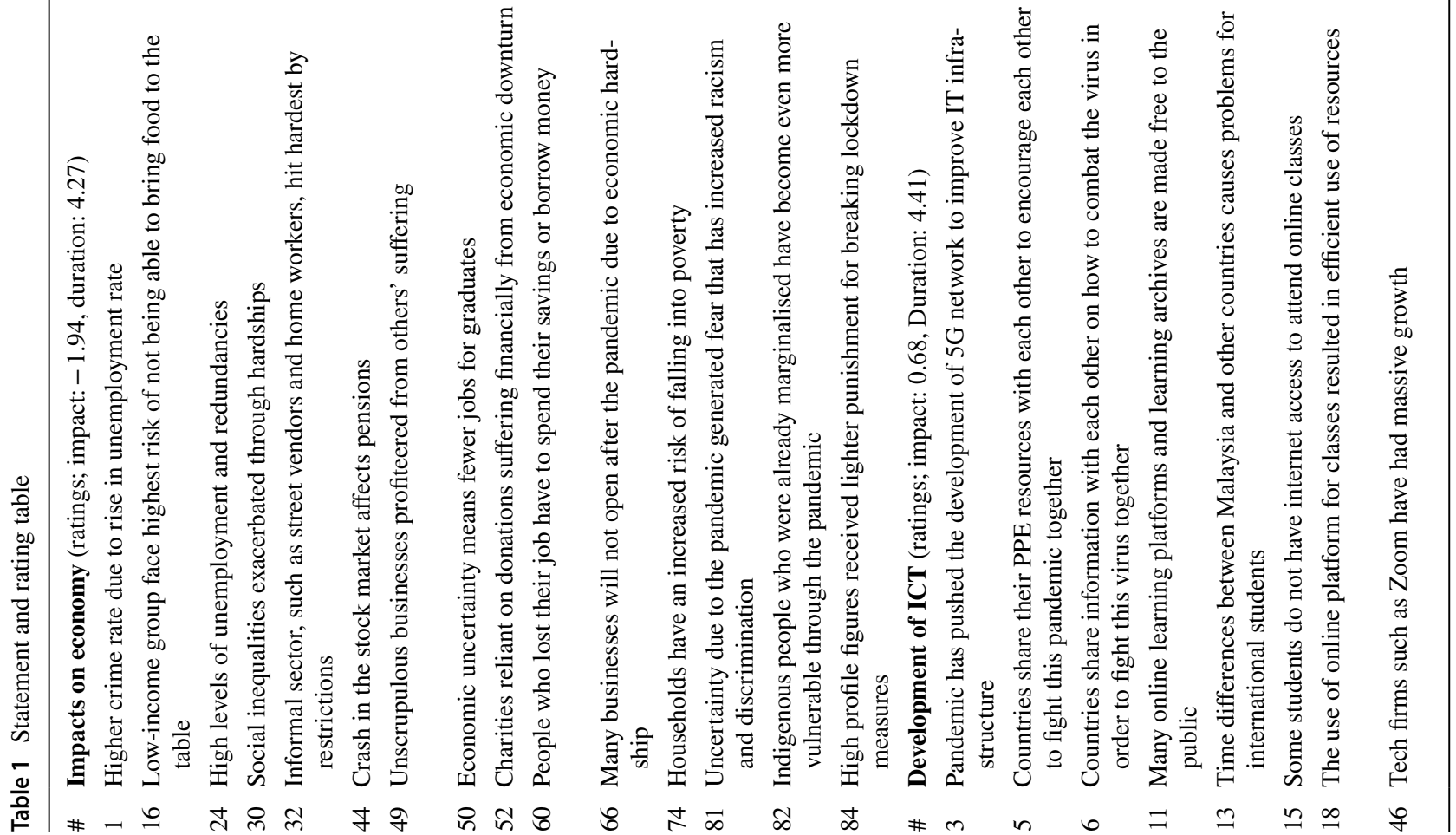




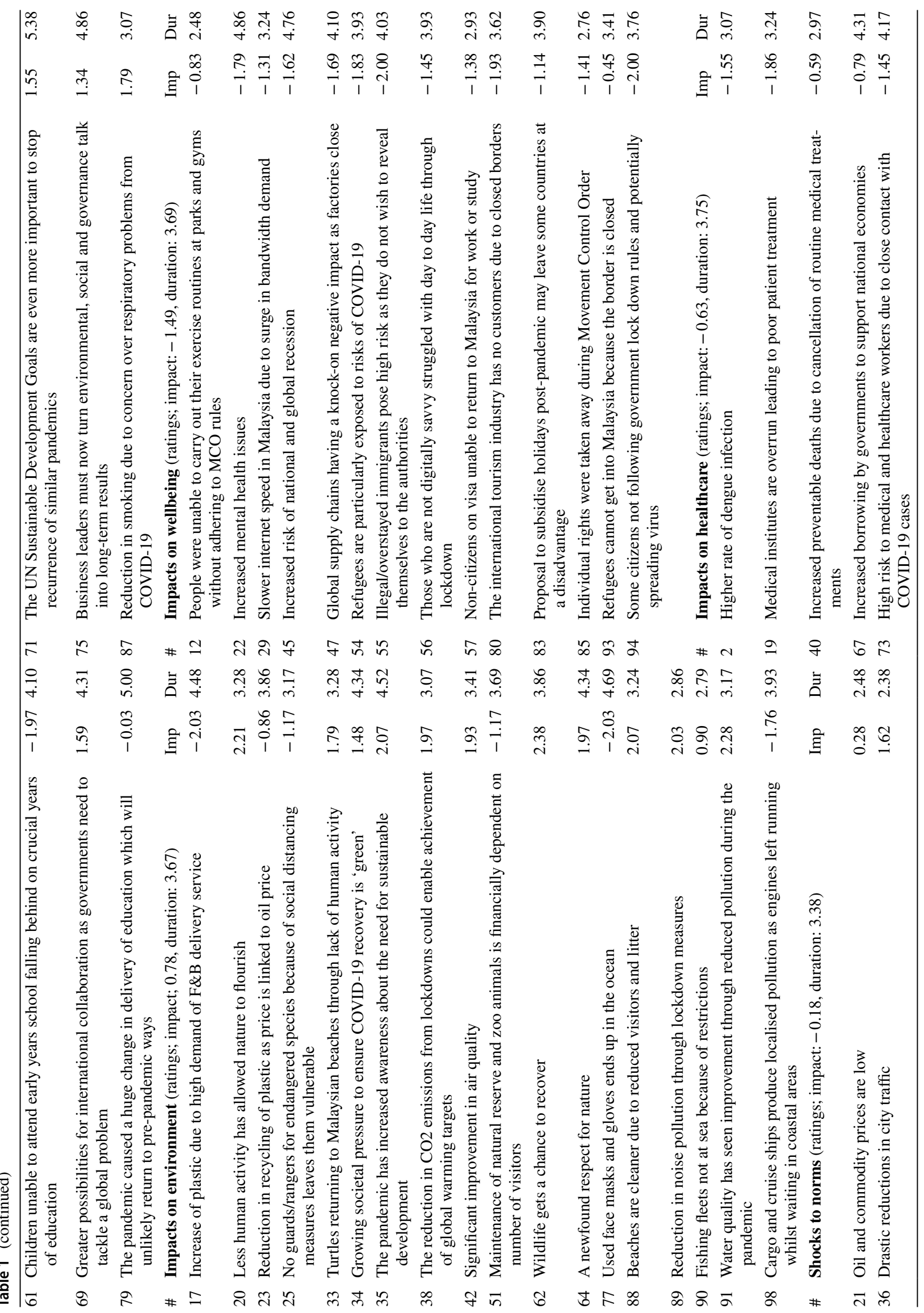


even more important to stop recurrence of similar pandemics. All three of these statements are work-in-progress prior to the COVID-19 pandemic. However, their importance has now been thrust to the forefront and the positive impact they bring will resound for a prolonged period.

\section{Discussion}

The results present diverse findings because a grounded approach was used to conduct this research to solicit opinions on the impacts COVID-19 on sustainability without restrictions. This created a broad conceptualisation, followed by the card sorting exercise where individual participants demonstrated their cognitive relationships between each statement, followed by the rating exercise to prioritise the reactive response towards these impacts. The following sub-sections analyse the cluster themes and their inherent statements.

\section{The impacts on the environment}

It was natural that environment was highlighted since COVID-19 pandemic was strongly attributed by mankind's encroachment on natural habitats. Out of 18 statements within the cluster, 6 items reported negative impacts. Participants raised concern over plastic pollution from online delivery services and used PPEs. While most of the statements were clearly positive or negative in impact, some statements were inconclusive such as \#90 'Fishing fleets not at sea because of restrictions' (mean $=0.90$ ) and \#70 'Increased human-nature interaction leads to increasing regularity of endemic and pandemic' (mean $=-0.21)$. The reduction of fishing activities facilitated recovery of marine environment. The wildlife also experienced recovery due to reduction of human activities. These positive impacts are at best temporary improvement because lockdown only postponed human activities and did not offer alternative solution for sustainable consumption. Based on participant's subjective assessment, the main forms of pollution such as air, water, soil and noise appeared to be under control during short-term restrictions. Air pollution is a particularly important aspect when considering the COVID-19 pandemic, as it is a respiratory disease; the review paper by Domingo et al. (2020) suggests that chronic exposure to certain air pollutants leads to more severe and lethal forms of COVID-19 and delays/ complicates the recovery of infected patients. Thus, cleaner air should keep patient recovery speedy and uncomplicated.

\section{The development of ICT}

As with most countries, the various types of movement restrictions due to COVID-19 pandemic forced millions 


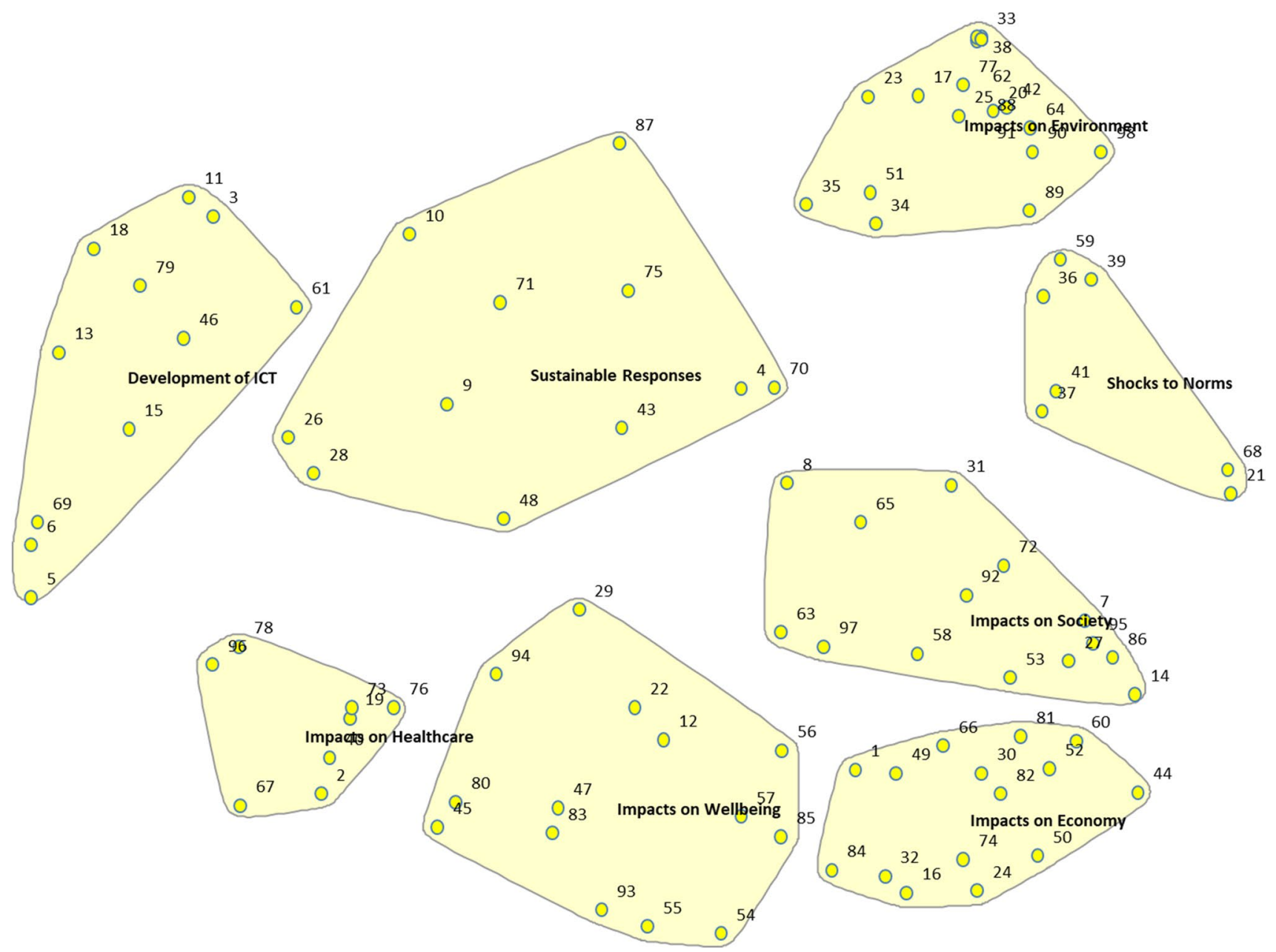

Fig. 1 Cluster point map

of workers to embrace remote working and learning. The capabilities of information and communications technology (ICT) infrastructure that support video conferencing and virtual collaboration applications are required to minimise disruption to businesses. This cluster covers a broad range of activities, where IT facilitates communication and information sharing in mitigating the spread of COVID-19. ICT have enabled online learning, but the digital divide experienced by rural and urban schools was exemplified by a viral news story of a student, who lives in the Malaysian state of Sabah, and was determined to sit for her online exam by securing connectivity to the network from the treetops (Lee, 2020). Such stories showed disparity of broadband access across the country apart from other challenges such as assess to e-learning system and gadget shortage. Nonetheless, the positive contribution of digital transformation at the retail industry did not go unnoticed although this cluster has not highlighted the impacts of e-commerce across various segments of the population. Zanoletti et al. (2021) proposed to adopt proactive approach towards digitisation during post-pandemic recovery phase, as part of their paper on raw material availability, because the major economy sectors slowed down due to insufficient supplies during lockdowns. In short, a more resilient economy needs to require businesses to take advantage of opportunities developed from digitisation.

\section{Sustainable responses}

This cluster is located at the centre of cluster map and seemed somewhat of a mix of ideas. The statements within the cluster are transitional in nature, for example statements such as \#26 'The disruption caused by pandemic has driven innovation within industry' and \#75 'Business leaders must now turn Environmental, Social and Governance talk into long-term results' demonstrate the urgency to innovate and adopt sustainable approaches that challenges the status quo of doing business. The average duration of this particular clusters is second highest at 4.29 , suggesting that this pandemic is building resilience into business as usual 
Fig. 2 Impact against duration plot

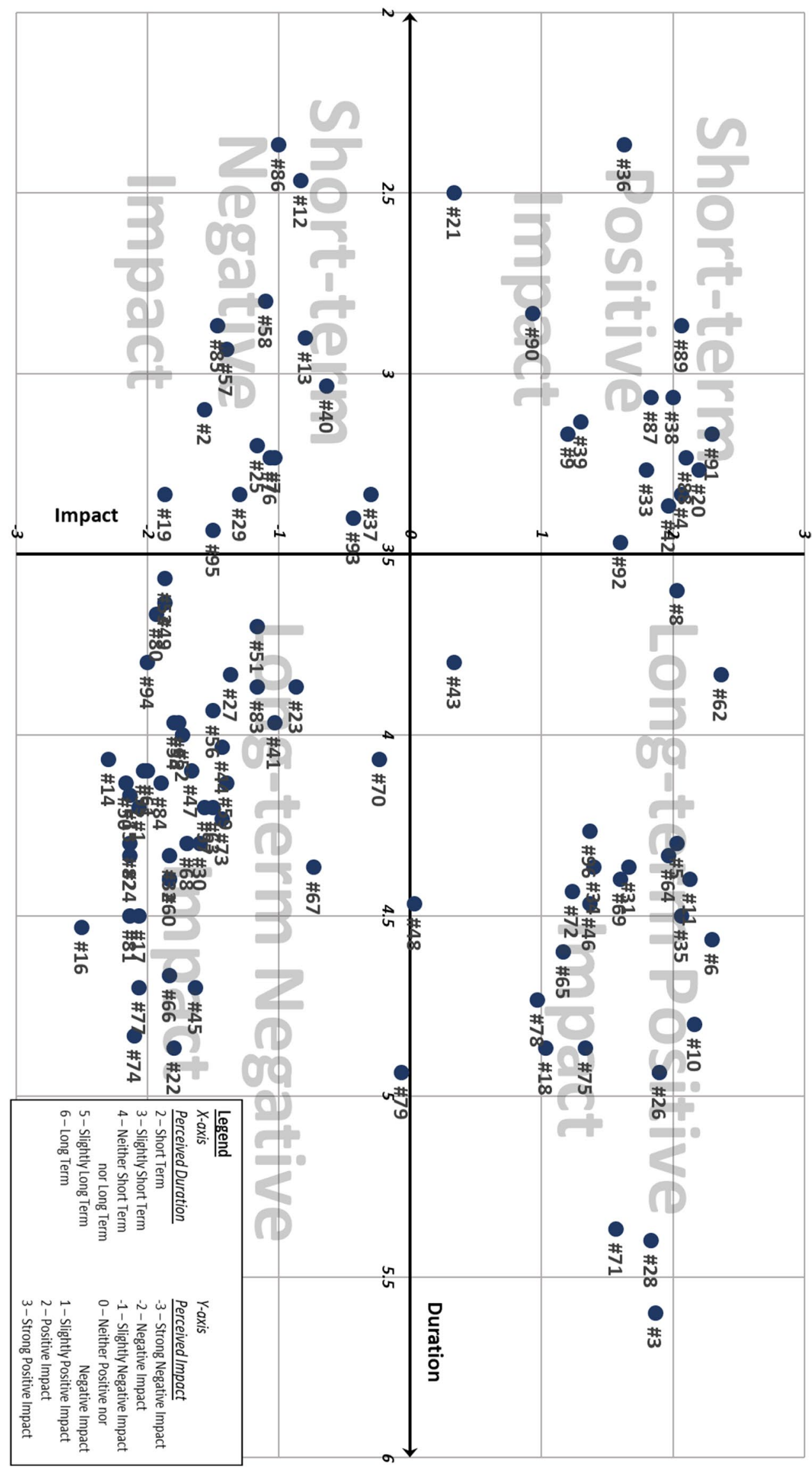


for future generations. This includes becoming receptive of sustainability-oriented business model, as seen in \#71 'The UNSDG are even more important to stop recurrence of similar pandemic'. Ikram et al. (2020a) explore how business can be certified to demonstrate their alignment to the UNSDG but also note that companies in developing countries struggle with the availability of resources. Such certification of businesses' sustainability efforts may allow the progress and recovery to be tracked post-pandemic. However, business is just one part of wider society, with Amato and Korhonen (2021) suggesting the complementary understanding of the circular economy, bio-economy and green economy providing important guidelines for sustainability transformations post-COVID-19. The larger question here may simply be has humanity learnt its' lessons from unsustainable practices?

\section{Shocks to norms}

Lockdown has proven that a healthier ecosystem and cleaner air is possible with reduced human activities. This cluster highlights disruptions in demand for transportation services, where the 'new normal' has slowed down the momentum of city traffic and air travels. In reality, the travel industry is profoundly affected by the unprecedented crisis and the Malaysian government have announced tax relief for domestic travel expenses incurred between March 2020 and December 2021. With regard to higher demand for energy, this was attributed to surge in domestic consumption during lockdown period as people spent more time indoors. Albeit temporary in negative impact, renewable energy source only accounts for $2 \%$ of total mix generated by the Malaysian energy industry (Abdullah et al., 2019). The Kuala Lumpur City Hall (DBKL) has since imposed 30\% reliance on renewable energy for future commercial and residential development projects to cut back on electricity cost (Bavani, 2020). This may have an impact upon COVID-19 patient recovery, as within the study by Coccia (2020b) suggests that types of energy resources and energy production may affect the environment and may accelerate the spread of COVID-19 and similar infectious diseases within society. Effectively, renewable energy is cleaner and creates less pollution, whilst more heavily pollution production of energy can exacerbate the factors that spread COVID-19 and increase the recovery time and mortality rate. This cluster also warned that \#68 'There will be a rush to recoup economic losses without concern for sustainability once the lockdown is lifted.' It maybe that in the pursuit of rapid economic recoveries around the world, any sustainability gains achieved diminishes in order to recoup losses. Within Ikram et al. (2020a, 2020b), they conclude that South Asian Association for Regional Cooperation (SAARC) need to mutually coordinate with the transition from fossil fuels to renewal energies. This study would suggest that the scope should be broaden to include Association of Southeast Asian Nations (ASEAN) countries as well; many of the SAARC and ASEAN countries face similar issues within their pursuits of sustainable development. If the 'new norm' of work from home is to be more energy intensive, then collaboration to build renewable energy capacity would appear to be the best way forward.

\section{The impacts on society}

Whilst this cluster has a mix of both negative and positive impacts leading to an average impact rating of -0.40 , it does pick up upon some key elements that are specific to the way government and stakeholders respond to the COVID19 pandemic. \#92 'All homeless put into shelters through Movement Control Order' showed that the plight of marginalised communities did not go unnoticed. The community spirit among Malaysian residents is highlighted, whereby \#8 'Compassion within the community led to communal production of PPE for front liners'. Nevertheless, the \#63 'Government in-fighting has led to a lot of uncertainty among citizen' and the presence of deadly variants threatens the nation's recoverability from the third wave infection. Coccia (2021c) states that resilient systems to pandemic shocks must have strong institutions and good governance driven by adequate and effective leadership that supports population needs. This leadership is further crucial in the decision making in collectivist culture but the mixed messages from ministers and the lack of enforcement to an already inadequate standard operating procedures are not helpful for quick recovery. Additionally, opposition parties are supposed to keep the ruling government in check but their differences and self-serving interest appear to be failing the people of Malaysia. A point to note here is that the study was conducted during the 1st wave of COVID-19 in Malaysia and whilst Coccia (2021d) suggests that some lessons can be learnt from prior waves from his case study in Italy, as it is different for Malaysia. This is because Malaysia successfully controlled the spread of 1 st wave of COVID-19 through strict and early lockdown, thus strategies were not developed or lessons not learnt to tackle subsequent waves of COVID-19 with more infectious variations such as the Delta variant. Thus, the impact upon society within the second, third and perhaps subsequent waves may have drastically different effects than the context this study is set.

\section{The impacts on economy}

The impacts towards business and national economies have been felt across the globe, with many businesses shutting down and driving up unemployment (Ikram et al., 2020a, 2020b). The lockdown restrictions extend the threat of recession in Malaysia. At least 1.36 million individuals (9.4\% total workforce) who works in the informal sector (DoSM, 
2017) are at risk of losing income due to temporary (or permanent) business closures. The \#32 'Informal sector, such as street vendors and home workers, hit hardest by restrictions', and \#66 'Many businesses will not open after the pandemic due to economic hardship'. This led to \#74 'Households have an increased risk of falling into poverty'. The low-income groups earn a minimum wage of 5.77 ringgits (US\$1.36) (Ashley, 2020) and \#60 'People who lost their job have to spend their savings or borrow money' thus straining retirement funds and possibly risking their future. Therefore, the government, being aware that \#16 'Low income group face highest risk of not being able to bring food to the table', recently approved one-off handouts under the PEMERKASA stimulus package to assist groups of people most affected by MCOs. These issues come amongst local authorities being expected to generate up to $25 \%$ less revenues, making it difficult to maintain current levels of service delivery, let alone invest in inclusive and sustainable development (Acuto et al., 2020). Thus, those in need of economic assistance the most may not be able to receive it. Economic recovery of majority industries will take at least 5 years to return to preCOVID-19 level. This statement coincides with the views of chief scientist of WHO, Dr. Soumya Swaminathan, who commented that it will take half a decade to control the crisis (CNBC, 2020). Thus, as Ikram et al. (2020a, 2020b) suggested within their study that industry needs to engage and evaluate sustainability differently to pre-pandemic times.

\section{The impacts on wellbeing}

The pandemic triggered \#22 'Increased mental health issues' among family member across all age groups, towards those staying together or separately. Extended restrictions induced seclusion and this condition does not sit well among collectivist culture. \#56 'Those who are not digitally savvy struggled with day to day life through lockdown' but many have quickly embraced video conferencing software and online shopping platform on their smartphones. However, Malaysian culture is very embedded with face-to-face interaction, including Friday prayers for the Muslim majority of the population and 'Makan' sessions where groups of friends dine together. However, among the factors to consider in reducing risk of spread is density of population and social interaction (Coccia, 2020a). Thus, this presents a challenge as isolation goes against the social norm; in fact, the second wave of COVID-19 was alleged to have been caused by a religious gathering. Furthermore, in the beginning, \#57 'Non-citizens on visa unable to return to Malaysia for work or study' but later on, entry was permitted to returning nationals and special long pass holders. This is in line with Askitas et al. (2021), where they suggested that international travel restrictions, although imposed early, had a short-lived effect due to the implementation of a less stringent travel restricting that failed to prevent the epidemic from turning into a pandemic When international travel was re-introduced, it came with mandatory quarantine and valid RT-PCR COVID-19 negative. The quarantine although posed another issue, as Bonati et al. (2021) suggested that the psychological impact of quarantine is substantial, with their findings suggesting that people need to understand what is happening, why and for how long. Whilst Bonati et al. (2021) highlighted psychological impact experienced by individualistic society such as Italy, the impact of isolation should be greater within collectivist society like Malaysia, where study was conducted. Additionally, the total number of foreign workers in Malaysia ranged from 2.96 to 3.26 million in 2017 (Loh et al., 2019), as well as some 178,140 refugees and asylum-seekers registered with UNHCR in Malaysia (UNHCR, 2020). Their social welfare and healthcare are equally important because virus variants do not discriminate between people. Everyone must be entitled to affordable screening and free vaccination to take part in quick recovery responses for societal wellbeing.

\section{The impacts on healthcare}

Similar to most countries, the concern for healthcare stems from what if the medical institutions become overwhelmed? Then how will patients be prioritised to receive medical attention for various illnesses? Within the context of this study, the 1st wave of COVID-19 in Malaysia, the government policy aligned with Coccia (2021a) in that as a developing country, the short-term focus was on measures of containment of a longer duration because of a weak healthcare sector based on low health expenditures. Whenever the healthcare systems run at or near capacity due to congestion, situations such as \#40 'Increased preventable deaths due to cancellation of routine medical treatments' becomes public health issues and limited intensive care unit (ICU) beds for emergency surgeries also raises humanity issues. If there were \#2 'Higher rate of dengue infection', the case of \#19 'Medical institutes are overrun leading to poor patient treatment' becomes inevitable. There is no justification for untimely death and healthcare management need the ruling government to cooperate in controlling the spread of virus. \#96 'Government should be open to criticism over response to corona virus'. With regard to international cooperation, this cluster also highlighted \#78 'Issues in global institutions, such as World Health Organisation, have become apparent under the consistent strain from the pandemic'. WHO's warning system on the international public health emergency must be reviewed due to its failure to curb the coronavirus outbreak.

The policy implications generated from this study can be developed from the eight clusters generated from the concept mapping: the development of ICT, sustainable responses, the impact on environment, shocks to norms, the impact 
on society, the impact on economy, the impacts on wellbeing and the impacts on healthcare. Whilst questions maybe raised over whether Malaysian Gen $\mathrm{Z}$ would be able to interpret such a complex concept as sustainable development, it appears that they have done so quite admirably. This is evidenced by much of the current literature being reinforced by what has been suggested within this study. When the indicators for duration and impact are brought into consideration and Fig. 2 is constructed, more tangible policy actions can be generated based upon the quadrant statements from the clusters fall into;

\section{Short-term positive impact}

Those statements that fall within this quadrant should focus upon policy to fully realise the potential by either trying to extend the duration of the item. For example; \#36 Drastic reductions in city traffic has a moderate positive impact but is considered one of the statements with the shortest durations. Thus, policy need to be implemented to prolong this benefit as long as possible. Could incentives be issued to companies to allow their employees to continue working from home?

\section{Long-term positive impact}

Statements within this quadrant should be the primary policy focus, as the long-term positive impact co-insides with the objective of sustainable development. Thus, policy should look at whether the positive impact can be further increased or the speed on implementation can be faster to have the benefits realised quicker. For example; \#3 Pandemic has pushed the development of $5 G$ network to improve IT infrastructure which can bring great benefits to communication and accessibility to all. However, as the previously discussed story of the Malaysian girl taking her exams from up a tree to get connectivity demonstrates the implementation is not complete and not evenly distributed, policy may focus upon these challenges to reap the benefits that can be gained.

\section{Short-term negative impact}

This quadrant poses a challenge, as with the short-term nature of the statements, policy may not be able to be enacted in time to deal with the consequences. All items in this quadrant are between 0 and -2 , which means that the worst impacts between -2 and -3 are not present. Policy here may simply try to mitigate or absorb the negative impacts. For example; \#86 People who practice religion have struggled to fulfil their spiritual needs with places of worship being closed demonstrated that very little can be done here, as spread of virus restricts gatherings. Thus clear directions and instructions that assist the re-opening of various economic sectors based on recovery phases should be taken to relief these impacts.

\section{Long-term negative impact}

Clearly this quadrant of the plot is of most concern, as not only do several statements fit within the largest negative impact (between -2 and -3 ) but also the duration of this negative impact. Whilst the perceived duration does not cross 5 out of a possible 7 offers the possibility that perhaps with policy introductions, the duration and the magnitude of these statements can be reduced and thus mitigate the worst effects. Statements such as \#16 Low income group face highest risk of not being able to bring food to the table has the highest impact rating and a moderately long duration too. This creates a key focus that policy needs to address this, as people should not be starving because they were unable to go to work. However, the severity of this statement actually created enough attention that before policy can into play, civil society acted and generated the 'White Flag Movement'. Malaysians in need of help displayed white flag to signal need for food and essentials and assistance being provided by neighbours, celebrities and businesses (BBC News, 2021).

Whilst this study has too many statements to generate policy response for each and every one, the above examples will hopefully demonstrate how the findings of this study can be utilised. This study is not without its limitations, especially the subjectivity involved, within mostly the initial qualitative brainstorming element. Whilst efforts were made to reduce the inherit subjectivity owing to the nature of qualitative component, it cannot be alleviated entirely. As this study remains within the conceptual domain, the limitations do not invalidate the results of this study. A further limitation comes from the cross-sectional nature of the study, with the pandemic being unprecedented and the future circumstance resulting from its spread unpredictable, participants responded based upon their current knowledge at the time. Future studies may choose to track the progress of the elements raised within this study and evaluate whether the durations and impacts are consistent with the participants estimates.

\section{Conclusion}

Within this study, a grounded theory approach was adopted to explore the perceptions of Malaysian Gen $\mathrm{Z}$ upon the impact COVID-19 pandemic would have upon the pursuit of sustainability. The results have demonstrated that the impacts of the COVID-19 have far reaching consequences and impact diverse aspects within the pursuit of sustainability, both negatively and positively. It is befitting that a 
lack of sustainability created the current pandemic situation, and it may well change the outlook upon sustainability in the future. It has now been estimated that it would have been 100 times cheaper to invest in sustainability to prevent the pandemic, then it is costing to cure the current pandemic (ipbes, 2020). Yet, with many of the positive impact being perceived to be materialise within moderate duration by the study's participants, it maybe that there is a return to business as usual. In which case, a more debilitating pandemic is not highly unlikely. Hopefully with the participants being Gen Z, who are more receptive about sustainability, these future leaders achieve more success at proactively incorporating sustainability within business practices or nationallevel policies.

Initial responses to COVID-19 suggest that drastic transformative change is possible and can be acceptable to many individuals (Bouman et al., 2021). Yet still the sustainable development challenges and climate change solutions are met with sluggish responses, but the outcome from these crises could be far more potentially disastrous. This study has demonstrated that not only did Malaysian Gen Z comprehend such a complex concept of sustainable development but through their perceptions of each component, tangible points are generated with both duration and impact they will have upon sustainable development. Whilst further research will be needed to test the perceptions of other demographics within Malaysian society, the results from this study align with much of the present literature. Practical implications are generated from how the negative impacts can be mitigated or have their duration reduced, whilst the positive impacts should look to be extended through a longer duration or ensured that they can be fully realised.

Author contribution STH collected the data for this study and conducted the analysis using the Concept System ${ }^{\circledR}$ Global MAX@ browser software followed by the initial drafting of the paper. KSK had the original idea for the piece of research and reworked the draft papers until final submission. Both authors read and approved the final manuscript.

Funding Not applicable.

Data availability The datasets used and/or analysed during the current study are available from the corresponding author on reasonable request.

\section{Declarations}

Ethics approval and consent to participate Ethics approval was granted by Sunway University Research Ethics Committee under the reference number SUREC 2020/058. Consent for the first stage (brainstorming) was achieved through presenting the participant information sheet (PIS) and a statement that the participants had read, understood and agreed to the PIS. The second round of data collection was far more complex and required participants to have individual logins, thus a complete consent form was signed, and participants provided with a PIS to keep.
Consent for publication Not applicable.

Competing interests The authors declare no competing interests.

\section{References}

Abdullah, W. S. W. O., Miszaina, Kadir, M. Z. A. A., \& Verayiah, R. (2019). The potential and status of renewable energy development in Malaysia. Energies, 12(2437).

Abiad, A., Arao, M., Dagli, S., Ferrarini, B., Noy, I., Osewe, P., Pagaduan, J., Park, D., \& Platitas, R. (2020). The economic impact of the COVID-19 outbreak on developing Asia. Retrieved from https://doi.org/10.22617/BRF200096

Acuto M, Larcom S, Keil R, Ghojeh M, Lindsay T, Camponeschi C, Parnell S (2020) Seeing COVID-19 through an urban lens. Nature Sustainability 3:977-978

Amato, D. D., \& Korhonen, J. (2021). Integrating the green economy, circular economy and bioeconomy in a strategic sustainability framework Ecological Economics, 188(107143).

Amran AB, Devi SS (2007) Corporate social reporting in Malaysia: an institutional perspective. World Review of Entrepreneurship, Management and Sustainable Development 3(1):20-36

Ang BS, Lim TC, Wang L (2018) Nipah virus infection. J Clin Microbiol 56(6):1-10

Ashley. (2020). New minimum wage gazetted. Retrieved from https:// www.thestar.com.my/news/nation/2020/01/14/new-minimumwage-gazetted

Bavani, M. (2020). 30\% renewable energy rule for all new projects. Retrieved from https://www.thestar.com.my/metro/metro-news/ 2021/05/17/30-renewable-energy-rule-for-all-new-projects

Askitas, N., Tatsiramos, K., \& Verheyden, B. (2021). Estimating worldwide effects of non-pharmaceutical interventions on COVID-19 incidence and population mobility patterns using a multiple-event study Scientific reports, 11(1972).

BBC News. (2020). Coronavirus: wild animals enjoy freedom of a quieter world. Retrieved from https://www.bbc.com/news/ world-52459487

BBC News. (2021). Malaysians in Covid lockdown fly white flags to ask for help. Retrieved from https://www.bbc.com/news/worldasia-57717214

Bernama. (2020). Turtle landings on the rise, positive impact from MCO. Retrieved from https://www.bernama.com/en/news. php?id=1854619Carey, A. (2020). Coronavirus: reusable cups banned from Starbucks, Coffee Club. Retrieved from https:// www.news.com.au/finance/business/retail/coronavirus-reusa ble-cups-banned-from-starbucks-coffee-club/news-story/d8407 38f512c7f12ee1cc47e335e53a9

Bigné JE, Aldás-Manzano J, Küster I, Vila N (2002) The concept mapping approach in marketing: an application in the travel agencies sector. J Cetacean Res Manag 5(2):87-95

Bonati, M., Campi, R., Zanetti, M., Cartabia, M., Scarpellini, F., Clavenna, A., \& Segre, G. (2021). Psychological distress among Italians during the 2019 coronavirus disease (COVID-19) quarantine BMC Psychiatry, 21(20).

Bouman T, Steg L, Dietz T (2021) Insights from early COVID-19 responses about promoting sustainable action. Nature Sustainability 4:194-200

CNBC. (2020). WHO warns it could take up to 5 years before the coronavirus pandemic is under control. Retrieved from https:// www.cnbc.com/2020/05/14/coronavirus-who-warns-it-couldtake-up-to-5-years-to-control-pandemic.html 
Coccia, M. (2020a). An index to quantify environmental risk of exposure to future epidemics of the COVID-19 and similar viral agents: theory and practice Environmental Research, 191(110155).

Coccia, M. (2020b). How (un)sustainable environments are related to the diffusion of COVID-19: the relation between Coronavirus disease 2019, Air Pollution, Wind Resource and Energy. Sustainability, 12(9709).

Coccia, M. (2021a). High health expenditures and low exposure of population to air pollution as critical factors that can reduce fatality rate in COVID-19 pandemic crisis: a global analysis Environmental Research, 199(111339).

Coccia M (2021b) How do low wind speeds and high levels of air pollution support the spread of COVID-19? Atmos Pollut Res $12: 437-445$

Coccia M (2021c) Pandemic prevention: lessons from COVID-19. Encyclopedia 1:433-444

Coccia, M. (2021d). The impact of first and second wave of the COVID-19 pandemic in society: comparative analysis to support control measures to cope with negative effects of future infectious diseases. Environmental Research, 197(111099).

Coccia, M. (2021e). The relation between length of lockdown, numbers of infected people and deaths of Covid-19, and economic growth of countries: lessons learned to cope with future pandemics similar to Covid-19 and to constrain the deterioration of economic system. Science of the Total Environment, $75(145801)$

Coccia, M. (2022). Preparedness of countries to face COVID-19 pandemic crisis: strategic positioning and factors supporting effective strategies of prevention of pandemic threats Environmental Research, 203(111678)

Convention on Biological Diversity. (2020). Malaysia - main details. Retrieved from https://www.cbd.int/countries/profile/?country= my

Davidson, J. (2020). Scientists warn worse pandemics are on the way if we don't protect nature. Retrieved from https://www.weforum.org/ agenda/2020/05/scientists-pandemics-coronavirus-nature-covid 19-health?fbclid=IwAR2BhgCWRBi2-JYzncJaTDuPuOZXt1Z51 0kJdpjcQysHODrGVHQoNDbsCWI

Domingo, J. L., Marques, M., \& Rovira, J. (2020). Influence of airborne transmission of SARS-CoV-2 on COVID-19 pandemic. A review Environmental Research, 188(109861).

DoSM. (2017). Informal Sector Work Force Survey Report, Malaysia, 2017 [Press release]

DoSM. (2020). Key Statistics of Labour Force in Malaysia, December 2020. Retrieved from https://www.dosm.gov.my/v1/index.php?r= column/cthemeByCat\&cat=124\&bul_id=RDllTkpHejRFNG1 RdIRLWWJzMi91QT09\&menu_id=Tm8zcnRjdVRNWWlpWjR1 bmtlaDk1UT09

Florizone, R. (2020). Three ways the coronavirus is shaping sustainable development. Retrieved from https://www.iisd.org/articles/threeways-coronavirus-shaping-sustainable-development

Gill, V. (2020). Coronavirus: This is not the last pandemic. Retrieved from https://www.bbc.co.uk/news/science-environment-52775386

Glick, D. (2004). The big thaw. National Geographic. Retrieved from https://www.nationalgeographic.com/environment/global-warmi ng/big-thaw/

Hansen D, Dunford B, Alge B, Jackson C (2016) Corporate social responsibility, ethical leadership, and trust propensity: a multiexperience model of perceived ethical climate. J Bus Ethics 137(4):649-662

Harrabin, R. (2018). Young will pick up climate change bill, advisers warn. Retrieved from https://www.bbc.com/news/science-envir onment-44634122
Homer ST (2021) Perceived corporate citizenship: a scale development and validation study adopting a bottom-up approach. Qual Quant. https://doi.org/10.1007/s11135-021-01184-w

Homer, S. T., \& Khor, K. S. (2021). Sustainable campus using concept mapping: a bottom-up approach engaging both staff and students. International Journal of Sustainability in Higher Education. Vol. ahead-of-print No. ahead-of-print. https://doi.org/10.1108/ IJSHE-02-2021-0059

Hughes, K. (2020). Protector or polluter? The impact of COVID-19 on the movement to end plastic waste. Retrieved from https://www. weforum.org/agenda/2020/05/plastic-pollution-waste-pandemiccovid19-coronavirus-recycling-sustainability?fbclid=IwAR0KboC VyZ_Crcbfgy2STErR51X0s5PyipwchhX1URpIpiiQQoQQ0m5_zI

Idemudia U (2011) Corporate social responsibility and developing countries: moving the critical CSR research agenda in Africa forward. Prog Dev Stud 11(1):1-18

Ikram M, Zhang Q, Sroufe R, Ferasso M (2020a) The social dimensions of corporate sustainability: an integrative framework including COVID-19 insights. Sustainability 12(20):8747

Ikram M, Zhang Q, Sroufe R, Shah SZA (2020b) Towards a sustainable environment: The nexus between ISO 14001, renewable energy consumption, access to electricity, agriculture and $\mathrm{CO} 2$ emissions in SAARC countries. Sustainable Production and Consumption 22:218-230

ipbes. (2020). Ipbes workshop on biodiversity and pandemics. Intergovernmental Platform on Biodiversity and Ecosystem Services.

Ipsos. (2020). Earth Day 2020: How do Great Britain and the world view climate change and COVID-19? Ipsos.

Jones, L., Palumbo, D., \& Brown, D. (2020). Coronavirus: a visual guide to the economic impact. Retrieved from https://www.bbc.com/news/ business-51706225

Kane M, Trochim WMK (2007) Concept mapping for planning and evaluation. Sage Publications Inc, USA

Kumari, P., \& Toshniwal, D. (2020). Impact of lockdown on air quality over major cities across the globe during COVID-19 pandemic. Urban Climate, 34, 100719.

Le Quéré C, Jackson RB, Jones MW, Smith AJP, Abernethy S, Andrew RM, Peters GP (2020) Temporary reduction in daily global CO2 emissions during the COVID-19 forced confinement. Nat Clim Chang 10:647-653

Lee, T. Y. (2020). Malaysian student sits exams in a tree to ensure good wifi. $B B C$ News, . Retrieved from https://www.bbc.com/news/blogsnews-from-elsewhere-53079907

Loh, W. S., Simler, K., Wei, K. W., \& Yi, S. (2019). Malaysia: Estimating the number of foreign workers. The World Bank. AUS0000681

Mahathir, M. (2008). Malaysia as a full developed country - one definition. Retrieved from https://www.pmo.gov.my/vision-2020/malay sia-as-a-fully-developed-country/

Mallick, S. K., Pramanikb, M., Maity, B., Das, P., \& Sahana, M. (2021). Plastic waste footprint in the context of COVID-19: reduction challenges and policy recommendations towards sustainable development goals. Science of the Total Environment, 796(148951).

MESTECC (2019) Malaysia's roadmap towards zero single-use plastics 2018-2030: towards a sustainable future. Ministry of Energy, Science, Technology, Environment and Climate Change, Malaysia

Preuss L, Barkemeyer R, Glavas A (2016) Corporate social responsibility in developing country multinationals: identifying company and country-level influences. Bus Ethics Q 26(3):347-378

Prevention and Control of Infectious Diseases (Measures within the Infected Local Areas) Regulations 2020. Retrieved from https:// amcham.com.my/wp-content/uploads/PREVENTION-ANDCONTROL-OF-INFECTIOUS-DISEASES-MEASURESWITHIN-THE-INFECTED-LOCAL-AREAS-REGULATIONS2020.pdf 
Rosas SR, Kane M (2012) Quality and rigor of the concept mapping methodology: a pooled study analysis. Eval Program Plann 35:236-245

Rume, T., \& Islam, S. D. U. (2020). Environmental effects of COVID-19 pandemic and potential strategies of sustainability. Heliyon, 6 (9).

Sarantakos S (2005) Social Research, 3rd edn. Palgrave MacMillan, Great Britain

Scaraboto, D., Joubert, A. M., \& Gonzalez-Arcos, C. (2020). Single-use plastic in the pandemic: how to stay safe and sustainable.

Settele, J., Diaz, S., Brondizio, E., \& Daszak, P. (2020). COVID-19 Stimulus measures must save lives, protect livelihoods, and safeguard nature to reduce the risk of future pandemics.

Shah AUM, Safri SNA, Thevadas R, Noordin NK, Abd Rahman A, Sekawi Z, Ideris A, Sultan MTH (2020) COVID-19 outbreak in Malaysia: actions taken by the Malaysian government. Int J Infect Dis 97:108-116

Sturrock K, Rocha J (2000) A multidimensional scaling stress evaluation 4880 Table. Field Methods 12(1):49-60

Tan, T., Sivanandam, H., \& Rahim, R. (2020). Over 30k SMEs have shuttered since the beginning of MCO, Parliament told. The Star. Retrieved from https://www.thestar.com.my/news/nation/2020/11/ 09/over-50k-smes-have-shuttered-since-the-beginning-of-mcoparliament-told?fbclid=IwAR1CuwW3re5wrX4Ec9ov1_GdJAk OeLh9s-KmNp70MCXyHWQXik5wqkib19w\#.X6jMxS_L9hA

The World Bank. (2020). The World Bank In Malaysia. Retrieved from https://www.worldbank.org/en/country/malaysia/overview

Tollefson, J. (2021). COVID curbed carbon emissions in 2020 - but not by much. Nature, 589 (343).
UNHCR. (2020). Figures at a Glance in Malaysia. Retrieved from https:// www.unhcr.org/en-my/figures-at-a-glance-in-malaysia.html

Walker, A. (2020). Developing world economies hit hard by coronavirus. Retrieved from https://www.bbc.com/news/business-52352395

World Health Organization. (2020). Nipah virus: key facts. Retrieved from https://www.who.int/news-room/fact-sheets/detail/nipah-virus

World Health Organization. (2020). Timeline: WHO's COVID-19 response. Retrieved from https://www.who.int/emergencies/disea ses/novel-coronavirus-2019/interactive-timeline?gclid=Cj0KC Qjwit_8BRCoARIsAIx3Rj744sUYF8gh-sKMcTrIa_POBUEeiAql eE9OO75_iYCmWuAA3uPQcPMaAv2lEALw_wcB\#

Yu, H., Ye, X., Zhang, M., Zhang, F., Li, Y., Pan, S., . . Lu, C. (2021). Study of SARS-CoV-2 transmission in urban environment by questionnaire and modeling for sustainable risk control Journal of Hazardous Materials, 420(126621).

Zanoletti, A., Cornelio, A., \& Bontempi, E. (2021). A post-pandemic sustainable scenario: what actions can be pursued to increase the raw materials availability? . Environmental Research, 202(111681).

Zulkifli N, Amran A (2006) Realising corporate social responsibility in Malaysia: A VIEW from the accounting profession. J Corp Citizsh 24:101-114

Publisher's note Springer Nature remains neutral with regard to jurisdictional claims in published maps and institutional affiliations. 